\title{
$\mathrm{QCA}$ 클록킹 방식의 D 플립플롭을 이용한 프로그램 가능한 양자점 셀 구조의 설계 ${ }^{\dagger}$
}

\section{(Design of Programmable Quantum-Dot Cell Structure Using QCA Clocking Based D Flip-Flop)}

\author{
신 상 호 $^{1)}$, 전 준 철 ${ }^{2)}$ \\ (Sang-Ho Shin and Jun-Cheol Jeon)
}

\begin{abstract}
요 약 본 논문에서는 QCA(quantum-dot cellular automata) 클록킹 (clocking) 방식의 D 플립 플롭의 구조를 제안하고, 이를 이용하여 프로그램 가능한 양자점 셀(programmable quantum-dot cell: $\mathrm{QPCA}$ ) 구조를 설계한다. 기존의 $\mathrm{QCA}$ 상에서 제안된 $\mathrm{D}$ 플립플롭은 클록 펄스의 신호로 동 작을 수행하기 때문에 이에 대한 입력 값을 임의로 설정해야 하고, $\mathrm{QCA}$ 클록킹과 중복되어 사 용하기 때문에 낭비되는 출력 값들이 존재했다. 이러한 단점을 개선하기 위해서 이진 배선과 클 록킹 기법을 이용하여 새로운 형태의 $\mathrm{D}$ 플립플롭을 제안하고, 이를 이용하여 $\mathrm{QPCA}$ 구조를 설 계한다. 이 구조는 입력을 제어하는 배선 제어 회로, 규칙 제어 회로, D 플립플롭, 그리고 XOR 논리 게이트로 구성된다. 설계된 $\mathrm{QPCA}$ 구조는 $\mathrm{QCADesigner}$ 를 이용하여 시뮬레이션을 수행하 고, 그 결과를 기존의 $\mathrm{D}$ 플립플롭을 이용하여 설계한 것과 비교·분석하여 효율성을 확인한다.
\end{abstract}

핵심주제어 : 프로그램 가능한 양자점 셀 구조, QCA 클록킹 기법, $\mathrm{D}$ 플립플롭, $\mathrm{QCADesigner}$

Abstract In this paper, we propose a $\mathrm{D}$ flip-flop based on quantum-dot cellular automata(QCA) clocking and design a programmable quantum-dot cell(QPCA) structure using the proposed D flip-flop. Previous D flip-flops on QCA are that input should be set to an arbitrary value, and wasted output values exist because it was utilized to duplicate by clock pulse and QCA clocking. In order to eliminate these defects, we propose a D flip-flop structure using binary wire and clocking technique on QCA. QPCA structure consists of wire control logic, rule control logic, D flip-flop and XOR logic gate. In experiment, we perform the simulation of QPCA structure using QCADesigner. As the result, we confirm the efficiency of the proposed structure.

Key Words : Quantum-Dot Programmable Cellular Automata, Quantum-dot cellular automata clocking technique, D flip-flop, QCADesigner

1. 서 론

\footnotetext{
† 이 논문은 2014년도 정부(미래창조과학부)의 재원으로 한국연 구재단의 지원을 받아 수행된 기초연구사업(2011-0014977)의 결과물임.

1) 경북대학교 컴퓨터학부, 제 1 저자

2) 금오공과대학교 컴퓨터공학과, 교신저자
}

무어의 법칙이 소개된 이래로 VLSI(vary large scale integrated circuit)내의 반도체 칩에 대한 집적 도(degree of integration)는 매년 2배 가까이 높아졌지 만 최근 $\mathrm{CMOS}$ 기술의 물리적인 한계로 인해 새로운 대체 기술의 필요성이 증대되고 있다. 양자점 셀룰러 오토마타(QCA; quantum-dot cellular automta)는 나 
노 스케일(nano scale)의 양자점에 기반을 둔 셀을 이 용하여 여러 가지 연산을 수행하고, 기존의 한계점을 해결하는 새로운 기술이다. Lent 등에 의해 처음으로 소개된 이래 $\mathrm{QCA}$ 의 기본 특성과 클록킹(clocking) 기 법을 이용해 기본적인 조합·순차 논리 회로 및 다중 값 논리(MVL; multi-valued logic) 회로까지 다양한 구조가 설계되었다[1-4].

한편, 프로그램 가능한 셀룰러 오토마타(PCA: programmable cellular automata)는 서로 다른 시간마 다 다른 규칙(rule)들을 이용하여 CA 셀(cell)들을 배 열하여 다음 상태로 진화(evolution)하는 것이다. 이러 한 $\mathrm{PCA}$ 는 메모리 혹은 $\mathrm{ALU}$ 의 구현에 효과적이지만 $\mathrm{CMOS}$ 기술에 의한 집적도의 한계로 인해 $\mathrm{QCA}$ 상에 서 새롭게 설계될 필요성이 존재한다. $\mathrm{QCA}$ 상에서 새로운 형태의 $\mathrm{PCA}$ 를 구현하기 위해서는 $\mathrm{D}$ 플립플롭 과 $\mathrm{XOR}$ 논리 게이트가 필요하다.[5]

기존에 제안된 $\mathrm{QCA}$ 상에서의 $\mathrm{D}$ 플립플롭과 $\mathrm{XOR}$ 논리 게이트는 다양하게 존재한다. 처음으로 제안된 설계 구조는 2개의 D 또는 SR 래치(latch)를 이용한 $\mathrm{D}$ 플립플롭[6]으로 기존의 전자회로에서 사용하던 방 식과 유사하게 설계되었다. 이 후 클록(clock)의 에지 트리거(edge trigger) 혹은 레벨 트리거(level trigger) 를 이용하여 새로운 유형이 제안[7]되었고, $\mathrm{QCA}$ 특성 을 이용한 $\mathrm{D}$ 플립플롭[7]도 제안되었다. 그러나 현재 까지 설계된 대부분의 $\mathrm{D}$ 플립플롭은 클록의 신호가 입력되는 경우에만 자신의 값을 출력하고, 새로운 값 을 입력받으며, 이를 설계한 구조는 $\mathrm{QCA}$ 에 존재하는 클록킹(clocking) 기법과 중복되어 수행되기 때문에 본래의 클록의 신호가 입력되지 않는 경우에도 $\mathrm{D}$ 플 립플롭 내에서 임의의 상태 값이 지속적으로 출력된 다. 이러한 $\mathrm{D}$ 플립플롭 설계 구조를 이용하여 대단위 의 회로를 설계하는 경우 지속적으로 출력되는 상태 값을 임의로 제어할 수 없게 되므로, 여러 문제를 유 발할 수 있다.

$\mathrm{QCA}$ 상에서 제안된 $\mathrm{XOR}$ 논리 게이트는 배선교차 (wire crossing) 기법의 사용 유무에 따라 두 가지 유 형으로 분류된다. 널리 사용되는 XOR 논리 게이트는 배선교차 기법을 이용한 것[8]으로 규칙적인 설계가 가능하고, 안정적인 출력 상태 값을 얻을 수 있으며, 불대수 식에 기반을 두어 다양한 형태로 설계가 가능 하다. 그러나 설계 구조의 크기와 입력과 출력 간의 지연시간(latency time)이 배선교차 기법에 따라 증가
되는 단점이 존재한다. 이러한 단점을 해결하기 위해 최근에는 배선교차 기법을 사용하지 않는 $\mathrm{XOR}$ 논리 게이트의 구조[9]가 제안되고 있고, 지연시간이 기존에 배선교차를 이용한 구조보다 단축되었다. 그러나 논리 게이트의 입·출력의 위치가 회로 내부에 존재하거나 출력되는 상태 값에 노이즈가 발생하기 때문에 이들 을 이용한 대단위 회로의 설계에서의 고려되는 확장 성과 융통성 측면에서는 단점이 존재한다.

본 논문에서는 기존의 $\mathrm{PCA}$ 를 대체하는 새로운 형 태의 $\mathrm{QCA}$ 에 기반을 둔 $\mathrm{PCA}(\mathrm{QPCA})$ 의 구조를 설계 한다. 설계하는 $\mathrm{QPCA}$ 는 기존에 제안된 배선교차를 사용하지 않는 $\mathrm{XOR}$ 논리게이트의 구조를 변형하여 사용하고, 새로운 형태의 $\mathrm{D}$ 플립플롭과 두 개의 $\mathrm{QCA}$ 배선(wire)를 연결하기 위한 배선 제어 회로(wire control logic), 규칙을 제어하기 위한 규칙 제어 회로 (rule control logic)를 제안한다. 설계된 $\mathrm{QPCA}$ 는 QCADesigner[10,11]를 이용하여 시뮬레이션을 수행하 고, 그 결과를 분석한다. 또한, 기존에 $\mathrm{QCA}$ 상에서의 제안된 $\mathrm{D}$ 플립플롭을 이용한 설계 구조와 본 논문에 서 설계한 것의 시/공간적(time/space) 효율성을 비교 하여 우수성을 검증한다.

본 논문의 구성은 다음과 같다. 2 장은 관련연구로 $\mathrm{QCA}$ 의 기본 개념과 기존에 제안된 $\mathrm{XOR}$ 논리 게이트 에 대해 소개한다. 3장에서는 $\mathrm{QCA}$ 를 이용한 $\mathrm{PCA}$ 셀 의 설계 구조를 설명한다. 4장에서는 QCADesigner를 통해 제안된 구조에 대한 시뮬레이션을 수행하고, 그 결과를 비교 및 분석한다. 마지막으로 5 장에서 결론을 맺는다.

\section{2. 관련 연구}

본 절에서는 $\mathrm{QCA}$ 의 기본 개념과 $\mathrm{QCA}$ 에 기반을 둔 $\mathrm{XOR}$ 논리 게이트에 대해 소개한다.

\section{$2.1 \mathrm{QCA}$ 의 기본 개념}

전형적인 $\mathrm{QCA}$ 셀은 정사각형 형태이고, 이를 표 준 셀(standard cell)이라 지칭한다. 셀 내부는 네 개의 양자점들이 각 모서리 부분에 위치하고, 전자들은 쿨 롱 반발력 때문에 가능한 멀리 떨어지려는 경향이 있 으며, 하나의 셀이 바닥상태(ground state)로 변경될 


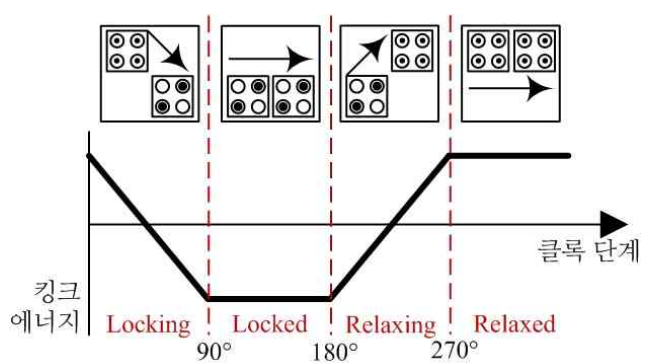

(a)

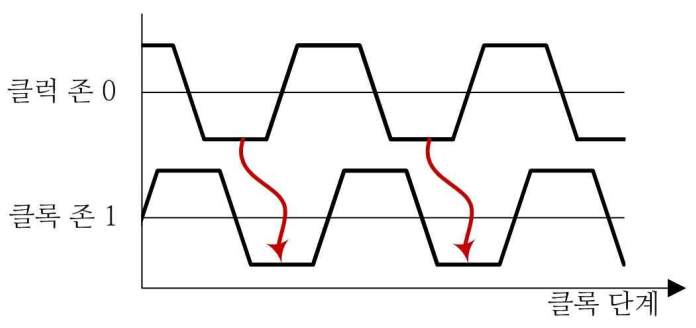

(b)

$<$ Fig. 1> A concept of QCA clocking: (a) four distinct QCA clock stages and (b) data transmission between two cells with different clock stages

경우 서로 반대 방향의 모서리 양자점 내에 전자들이 각각 존재하게 된다. 그 결과로 셀 내의 전자들이 양 자점 내부에 존재하는 형태는 두 종류로 나뉘고, 이를 편극화(polarization) 현상이라 지칭한다. 또한, 바닥상 태에서의 편극 값 1 또는 -1 은 이진논리 값 1 과 0 에 각각 대응된다[8,12-15].

한편, QCA 셀로 설계된 모든 회로는 선 형태의 배 열로 구성되어 있고, 이를 이진 배선(binary wire)이라 하며, 이러한 배선을 이용해 두 종류의 논리게이트를 표현할 수 있다. 대각선의 위치에 놓인 두 셀의 쿨롱 반발력에 대한 관계를 이용한 정규적인 인버터(INV; formal inverter)와 서로 다른 세 개의 배선이 만날 경 우 각각의 배선 편극 값에 따라 출력되는 값이 상반 되는 다수결(MV; majority voting) 게이트가 존재한 다. 예를 들어, 입력 $\mathrm{A}, \mathrm{B}, \mathrm{C}$ 의 편극 값이 각각 1 , $-1,+1$ 인 경우 -1 값이 +1 값에 비해 상대적으로 다 수이므로 출력되는 값은 -1 이 된다. 또한, $\mathrm{MV}$ 게이 트 내의 하나의 입력을 편극 값 -1 또는 +1 로 영 구히 고정할 경우 이것은 전자회로의 $\mathrm{AND}$ 또는 $\mathrm{OR}$ 게이트 역할을 각각 수행할 수 있다[12-15].

이진 배선은 단순히 QCA 셀들로만 구성되어 있기 때문에 이들을 통한 임의의 상태 값 전송은 불가능하
다. 이러한 단점을 보완하기 위해 클록킹 기법이 제 안되었고, 이를 상태 전이(state transition) 기법이라고도 부른다. 상태 전이 기법은 각 셀들의 준단열 스위칭 (quasi-adiabatic switching)과 터널링 장벽(tunneling barrier)을 통해 이루어진다. 준단열 스위칭의 전압의 인가여부에 따라 터널링 장벽의 높이가 변경되면서 각 셀들은 임의의 단계로 변화되고, 이는 Fig. 1.(a)와 같이 수행된다. 하나의 셀은 터널링 장벽의 높낮이에 따라 서로 다른 네 개의 클록 단계를 나타내고, 이는 터널링 장벽이 올라가는 잠기는(locking) 단계, 터널링 장벽이 완전히 올라간 잠김(locked) 단계, 터널링 장벽 이 내려가는 완화되는(relaxing) 단계, 그리고 터널링 장벽이 완전히 내려가 있는 완화(relaxed) 단계로 구 성되어 있다. 잠김 단계에서는 터널링 장벽이 완전히 올라가 있어 전자들의 움직임 없이 편극화 값 +1 또 는 -1 중 하나로 결정되기 때문에서 이때의 킹크 에 너지(kink energy)는 매우 낮은 값 즉, 바닥상태를 유 지하게 된다. 반대로 완화 단계는 터널링 장벽이 완전 히 내려가 있기 때문에 전자들이 자유롭게 움직이는 자유 전자 상태가 유지되고, 이때의 킹크 에너지 값은 가장 높다.[8,12-15] 한편, $\mathrm{QCA}$ 배선 내에서 특정 상 태 값을 전송하기 위해서는 Fig. 1(b)와 같이 인접하 는 두 셀 간에 클록 단계가 각각 잠김과 잠기는 상태 이어야 한다. 즉, 데이터를 전송하고자 하는 셀은 클 록 존 0 에 해당하고, 데이터를 전송받고자 하는 셀은 클록 존 1 에 해당할 경우 클록 존 0 이 잠김 단계이면 서, 동시에 클록 존 1 이 잠기는 단계일 경우 이웃하는 두 셀 간의 데이터 전송이 가능한 것이다. 이것은 이 미 하나의 상태 값을 소유하고 있는 클록 존 0 과 잠 기는 과정에서 이웃하는 셀과 쿨롱 반발력 때문에 클 록 존 1 또한 클럭 존 0 과 동일한 상태 값을 소유하 게 되는 것이다. 이러한 원리를 통하여 배선 내에서 셀들 간의 데이터 전송이 가능한 것이다. 본 논문에서 는 이러한 $\mathrm{QCA}$ 클록킹 기법을 이용하여 새로운 형태 의 $\mathrm{D}$ 플립플롭을 설계한다.

\section{2 기존의 $\mathrm{QCA}$ 상에서 제안된 $\mathrm{D}$ 플립플롭}

기존에 $\mathrm{QCA}$ 상에서 제안되었던 $\mathrm{D}$ 플립플롭은 Fig. 2 와 같다. 이들은 기존의 전자회로의 설계에서 사용 되던 Fig. 2(a)와 같은 마스터-슬레이브(master-slave) [6] 또는 Fig. 2(b)와 같은 에지 트리거의 형태[7]를 
이용하여 제안되었기 때문에 별도의 클록 펄스(CLK; clock pulse)를 입력으로 두어 회로의 입력(D)과 출력 $(\mathrm{Q})$ 을 제어한다. 그러나 $\mathrm{QCA}$ 클록킹 기법과 중복 사 용되어 기존의 $\mathrm{CLK}$ 신호의 입력이 존재하지 않는 경 우에도 Fig. 2(a)와 2(b)의 시뮬레이션 결과와 같이 지 속적으로 상태 값이 $\mathrm{D}$ 플립플롭으로부터 출력됨을 확 인할 수 있다. 또한, Fig. 2(b)와 같이 CLK 신호의 입 력 주기를 증가할 경우 낭비되는 출력 상태 값들이 증가한다는 것을 알 수 있다. 이러한 구조를 이용하여 대단위 회로를 설계할 경우 $\mathrm{CLK}$ 에 의해 제어된 출력 상태 값 이외의 낭비되는 값들에 대한 제어 회로를 별도로 설계해야 하고, 설계하고자 하는 회로의 크기 에 따라 입·출력간의 지연시간도 늘어나기 때문에 $\mathrm{QCA}$ 속성을 이용한 새로운 형태의 $\mathrm{D}$ 플립플롭의 설 계가 필요하다.
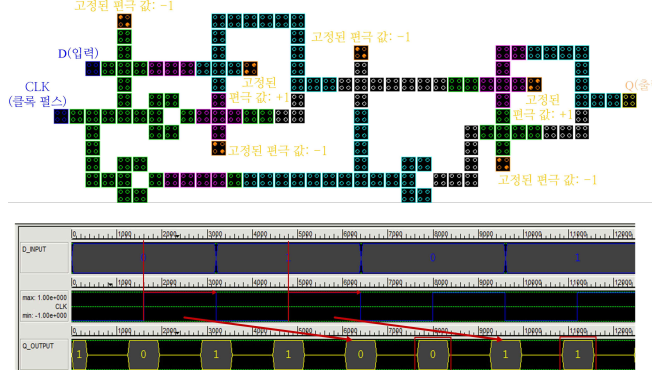

(a)
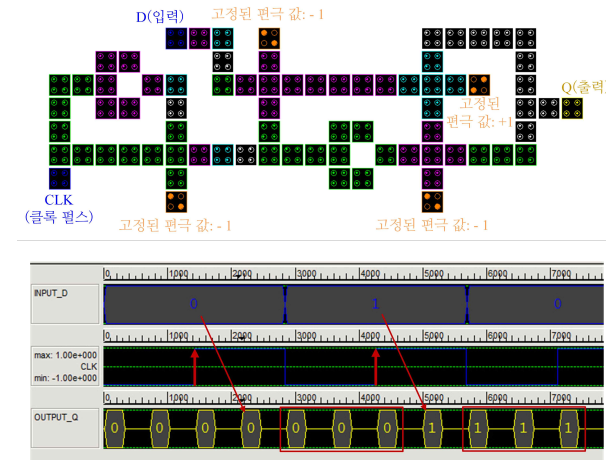

(b)

<Fig. 2> Previous D flip-flop structure: (a) layout of master-slave combination and (b) layout of edge trigger

3. $\mathrm{QPCA}$ 의 구조 설계
본 절에서는 $\mathrm{QPCA}$ 의 구조 설계 시 필요한 $\mathrm{D}$ 플립 플롭을 새롭게 제안하고, 기존의 $\mathrm{D}$ 플립플롭과 제안 한 것을 이용하여 $\mathrm{QPCA}$ 의 구조를 각각 설계한다.
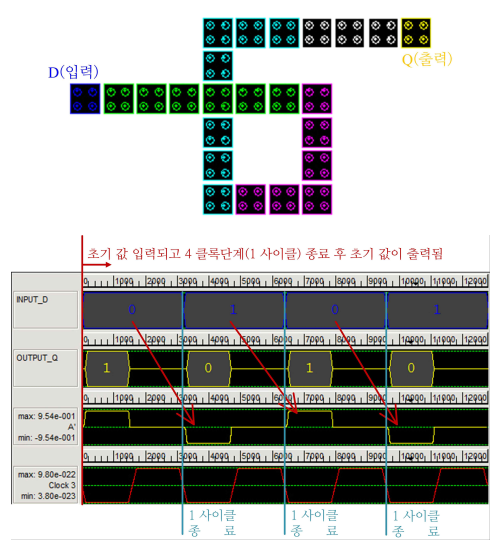

(a)

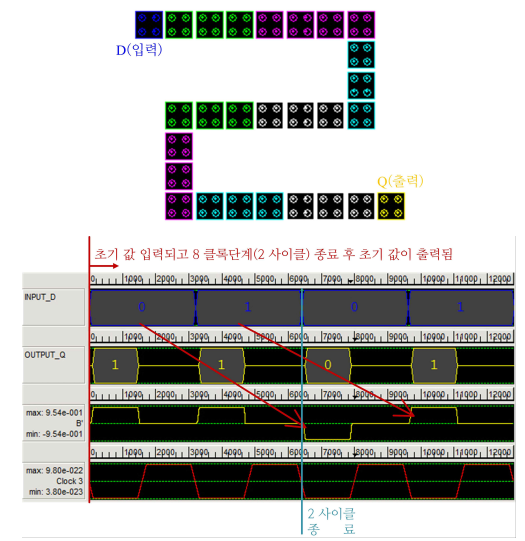

(b)

$<$ Fig 3> Proposed D flip-flop using QCA clocking and binary wire: (a) layout of having 4 clocks and (b) layout of having 8 clocks

\section{1 새로운 D 플립플롭 구조의 제안}

$\mathrm{QCA}$ 상에서 새롭게 제안하는 $\mathrm{D}$ 플립플롭은 기존의 전자회로에서 사용하던 것과 달리 $\mathrm{CLK}$ 의 신호에 대 한 입력 없이 $\mathrm{QCA}$ 클록킹과 이진 배선을 이용하여 설계한다. 기존의 $\mathrm{D}$ 플립플롭의 역할은 $\mathrm{CLK}$ 신호의 입력에 따라 임의의 상태 값을 저장하거나 출력하는 것이었다. 이것은 기존 회로의 로직이나 배선형태가 $\mathrm{CLK}$ 의 신호에 따라 동기화가 수행되기 때문이나 $\mathrm{QCA}$ 에서는 배선이 셀들로 구성되어 있기 때문에 별 


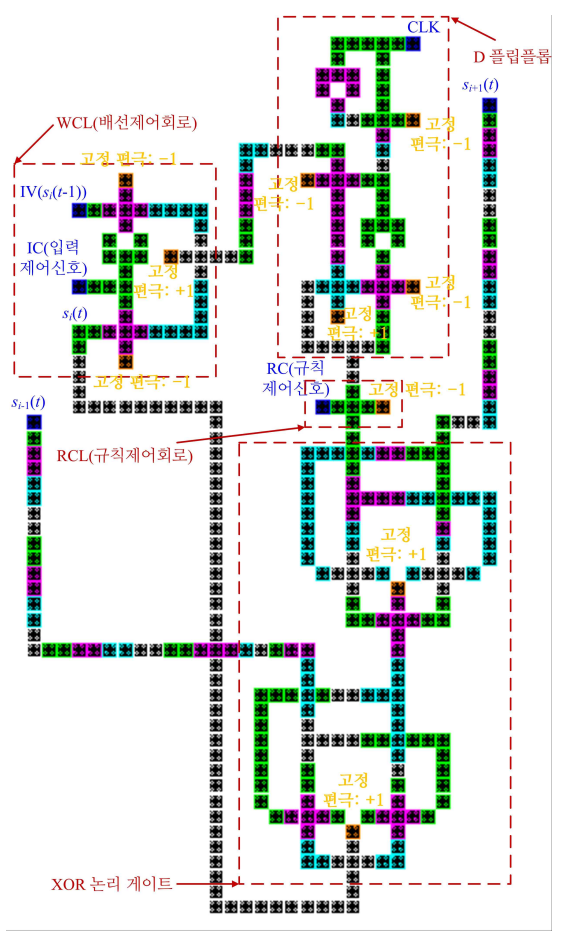

$<$ Fig. 4> Structure of QPCA using the previous D flip-flop

도의 CLK 신호 없이 클록킹 기법을 통해 데이터의 전송이나 지연 기능이 가능하다. 본 논문에서 제안하 는 $\mathrm{D}$ 플립플롭의 구조는 단순한 이진 배선 형태로 설 계되고, 기존의 것과 동일하게 일정 시간동안 지연 또 는 저장의 효과를 제공하며, 제안하는 구조는 Fig. 3 과 같다. Fig. 3(a)와 3(b)는 입·출력 간의 지연시간이 각각 4 와 8 클록인 D 플립플롭의 형태를 각각 나타내 고, 이들의 지연시간은 설계되는 회로의 전체 크기 또 는 소요되는 클록 개수에 따라 다르게 설계할 수 있 으며, 이들의 구조는 상황에 따라 자유롭게 구현할 수 있다. 또한, 기존의 CLK 신호로 제어되던 것과 달리 $\mathrm{QCA}$ 클록킹에 의해 상태 값이 출력되므로 버려지는 값이 없다는 장점이 존재한다.

\section{$3.2 \mathrm{QCA}$ 클록킹에 기반을 둔 $\mathrm{D}$ 플립플롭 구조를 이용한 $\mathrm{QPCA}$ 의 설계}

제안하는 $\mathrm{D}$ 플립플롭의 효율성을 측정하기 위해 기 존의 $\mathrm{D}$ 플립플롭과 제안한 구조를 이용하여 각각
$\mathrm{QPCA}$ 의 구조를 설계한다. $\mathrm{QPCA}$ 는 $\mathrm{D}$ 플립플롭과 $\mathrm{XOR}$ 논리게이트, 두 개의 $\mathrm{QCA}$ 배선(wire)를 연결하 기 위한 배선 제어 회로(WCL; wire control logic), 규 칙을 제어하기 위한 규칙 제어 회로(RCL; rule control logic)로 구성되어 있다. 이 때 사용되는 규칙 은 90 과 150 이고, 이 중 하나를 선택하는 것이 $\mathrm{RCL}$ 의 역할이다.

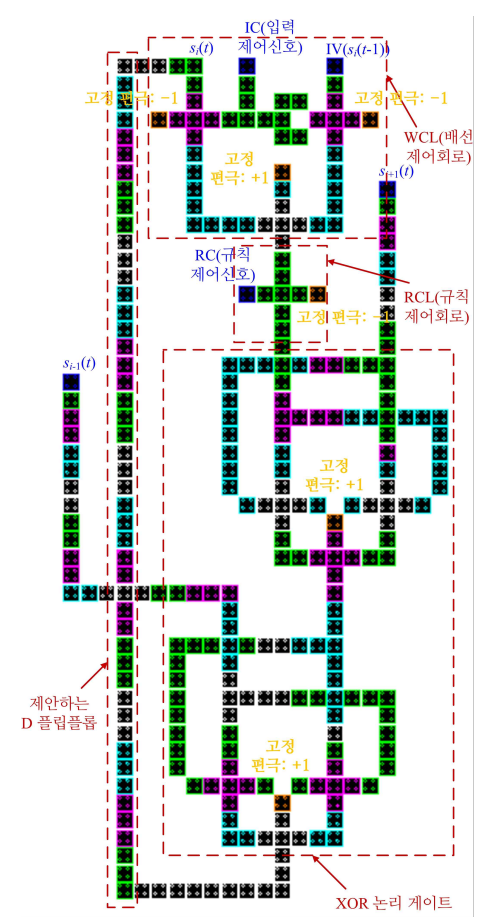

$<$ Fig. 5> Structure of QPCA using the proposed D flip-flop

기존에 제안되었던 $\mathrm{D}$ 플립플롭과 새롭게 제안한 것 을 이용하여 $\mathrm{QPCA}$ 구조를 설계하기 위해 다음의 내 용을 가정한다. 현재 번째 $\mathrm{QPCA}$ 는 $t$ 번째 시간 단계 에서 상태 값 $s t$ )를 $\mathrm{D}$ 플립플롭 내에 저장한다고 가 정하고, 현재 클록 펄스(CLK; clock pulse)의 신호는 0 이다. 만약 $\mathrm{CLK}$ 의 신호가 1 이 될 경우 $\mathrm{D}$ 플립플롭 의 현재 상태 값 $s_{i}(t)$ 을 출력하고, 이 때 출력된 상태 값 $s_{i}(t)$ 와 함께 규칙 90 과 150 중 하나를 선택하여 자신의 이웃의 상태 값인 $s_{i-1}(t)$ 와 $s_{i+1}(t)$ 와 함께 $\mathrm{XOR}$ 불대수 연산을 수행한 후 다음 시간 단계의 상 태 값 $s_{i}(t+1)$ 을 출력하는 동시에 이것은 $\mathrm{D}$ 플립플 롭의 입력 상태 값이 된다. 이러한 과정을 수행하는 
$\mathrm{QPCA}$ 의 구조는 Fig. 4와 같다.

$\mathrm{WCL}$ 은 초기의 입력과 이 후 CLK의 신호에 따라 출력되는 $\mathrm{D}$ 플립플롭의 상태 값에 대한 입력을 선택 하는 역할을 수행하는 것으로 기존의 전자회로에서의 배선은 단순히 신호의 인가 유무에 대한 역할만 수행 했지만 QCA 상에서의 배선은 셀들로 구성되어 있기 때문에 동일 평면상에서의 배선 연결은 특별한 회로 로 구성해야 한다. 설계한 구조에서는 멀티플렉서의 개념을 이용하여 임의의 입력제어신호(IC: input control signal)를 두고, 이를 이용하여 두 배선의 입력 을 제어한다. RCL은 규칙 90 과 150 중 하나를 선택하 기 위해 설계된 회로로써 단순히 자기 자신을 참조할 것인지에 대한 결정을 수행하는 역할이고, 이를 구현 하기 위해 $\mathrm{MV}$ 게이트를 사용하며, 하나의 입력을 영 구히 편극 값 1 로 고정한다. $\mathrm{D}$ 플립플롭은 기존의 에지트리거에 기반을 둔 구조를 이용하고, 두 개의 $\mathrm{XOR}$ 논리게이트를 사용한다.

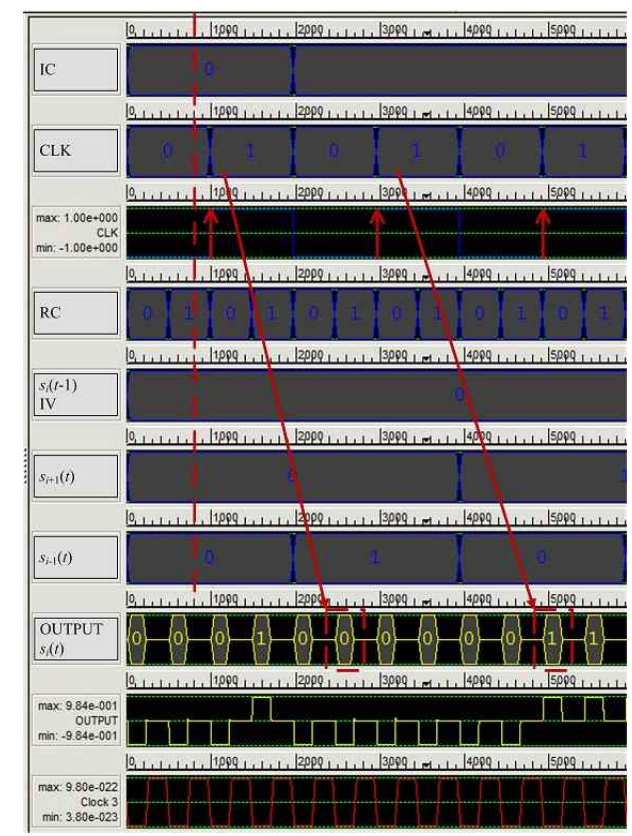

$\langle$ Fig. 6 $>$ The simulation result of QPCA structure using the previous D flip-flop

제안하는 $\mathrm{D}$ 플립플롭을 이용하여 설계한 $\mathrm{QPCA}$ 의 구조는 Fig. 5와 같다. D 플립플롭을 제외한 나머지 회로는 Fig. 4와 동일하므로 이에 대한 자세한 설명은 생략한다. Fig. 4 의 D 플립플롭의 구조와는 다른 이진
배선형태의 구조지만 입력과 출력간의 지연시간이 16 클록이고, 단순히 $\mathrm{QCA}$ 클록킹 방식을 이용하기 때문 에 기존의 CLK 신호를 이용하여 D 플립플롭의 동작 을 수행하던 것과 달리 매우 간소화된 형태이다. 또한 $\mathrm{CLK}$ 의 신호와 $\mathrm{QCA}$ 클록킹이 중복되어 동작이 수행 되기 때문에 출력에서 낭비되는 상태 값이 발생하지 만 제안한 $\mathrm{D}$ 플립플롭을 이용한 $\mathrm{QPCA}$ 의 구조에서는 16 클록 이후에는 4 클록마다 규칙적으로 결과 값이 출력된다. 본 절에서 설계한 $\mathrm{QPCA}$ 구조에 대한 성 능 평가는 다음 절에서 설명한다.

\section{4. 성능평가}

본 절에서는 설계한 두 $\mathrm{QPCA}$ 구조에 대한 성능평 가를 위해 QCADesigner[10,11]를 이용해 시뮬레이션 을 수행하고, 그 결과를 비교 분석한다.

$\mathrm{QCA}$ 에 기반을 두어 설계한 회로에 구현 또는 시뮬레 이션은 두 가지 기법으로 수행되고, 이를 코히런 트 벡터(coherent vector)와 쌍(안정)근사(bistable approximation)라고 지칭하며, 두 방법에 대한 시뮬레이 션은 각각의 기반을 두는 개념에 따라 약간의 차이를 두고 수행된다. 코히런트 벡터 방식의 시뮬레이션은 밀도행렬접근(density matrix approach)에 기반을 두 고, 시간에 따라 에너지의 준위가 달라지는 모델을 이 용하여 킹크(kink) 에너지 평가한다. 이에 반해 쌍근사 방식의 시뮬레이션은 두 가지 상태(편극 값: +1 과 -1 )에 기반을 두고, 이 들이 $\mathrm{QCA}$ 셀 간에 미치는 영향을 킹크 에너지로 계산하여 평가한다[10].

본 논문에서는 설계한 구조를 특정한 상태 값으로 설정하여 시뮬레이션을 수행하기 때문에 쌍근사 방식 을 사용한다. QCADesigner는 이러한 두 가지 시뮬레 이션 기법을 수행할 수 있도록 구현된 소프트웨어로 서 본 논문에서는 이것을 이용하여 시뮬레이션을 수 행했다.

기존의 $\mathrm{D}$ 플립플롭을 이용해 설계한 $\mathrm{QPCA}$ 구조에 대한 시뮬레이션 결과는 Fig. 6과 같다. 설계한 구조 는 입력에 대해 올바른 결과 값이 출력됨을 확인했고, 에지 트리거 형태의 D 플립플롭을 사용했기 때문에 $\mathrm{CLK}$ 의 신호가 상승 에지(positive edge)일 경우에 D 플립플롭 내에 저장된 임의의 상태 값이 출력되고, $\mathrm{RC}$ 에 따라 $\mathrm{D}$ 플립플롭으로 출력된 상태 값의 참조 
여부를 결정한 후 자신의 이웃 상태 값인 $-1 t$ )와 $s_{i+1}(t)$ 를 이용해 XOR 불대수 연산을 수행한 후 다 음 $\mathrm{CLK}$ 의 신호를 기다린다. 설계한 구조의 입·출력간 의 지연시간은 20 클록이 소요되지만 최초의 출력 상 태 값은 WCL로부터 입력되기 때문에 24 클록이 소요 된다. 한편, CLK의 신호는 20 클록을 주기로 발생하 도록 설정하여 시뮬레이션을 수행했고, 그 결과 임의 의 상태 값이 출력된 후 다음 상태 값이 출력되기 전 까지 4 개의 낭비되는 값들이 발생했다. 이러한 낭비되 는 값들을 줄이기 위해 CLK의 입력을 영구히 (편극 값: +1 )로 고정하는 방법을 이용할 수 있지만 이것은 $\mathrm{D}$ 플립플롭 본연의 역할인 지연 효과를 수행할 수 없 기 때문에 실제로는 불가능하다.

한편, 제안한 $\mathrm{D}$ 플립플롭을 이용해 설계한 $\mathrm{QPCA}$ 구조에 대한 시뮬레이션 결과는 Fig. 7과 같다. 이 구 조 역시 입력에 대해 올바른 결과의 상태 값이 출력 됨을 확인했다. 제안한 $\mathrm{D}$ 플립플롭은 $\mathrm{QCA}$ 클록킹 기 법에 의해 제어되는 것이기 때문에 기존의 것과 달리 별도의 CLK 신호의 입력이 필요 없었고, 단순히 배선 연결의 선택과 규칙 90 과 150 중 하나를 선택하기 위 해 별도의 $\mathrm{IC}$ 와 $\mathrm{RC}$ 의 입력을 시뮬레이션을 수행하기 전에 설정했다. 초기의 $\mathrm{RC}$ 값은 0 으로 설정했기 때문

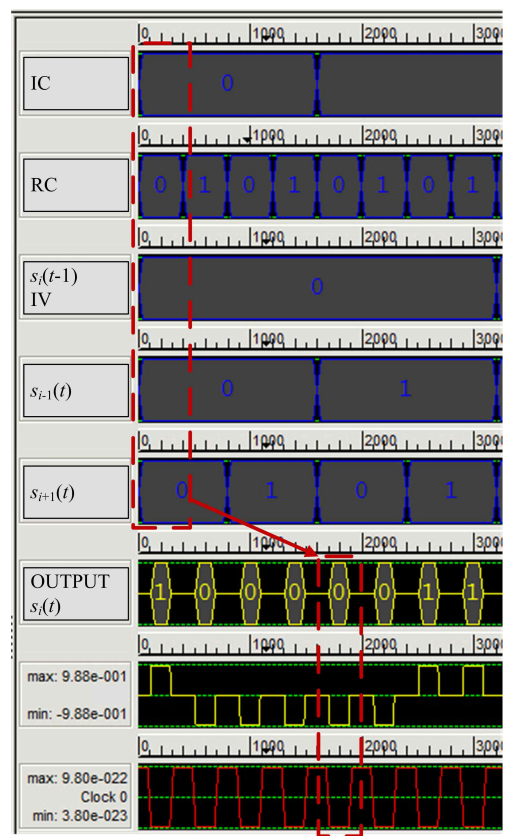

$<$ Fig. 7> The simulation result of QPCA structure using the proposed D flip-flop
에 $s_{i}(t)$ 은 참조하지 않고, 이웃 값들인 $s_{i-1}(t)$ 와 $s_{i+1}(t)$ 만 참조하여 처음으로 출력되는 상태 값은 0 이 되었고, 다음 시간 단계 $(t+1)$ 에서 출력되는 상태 값 역시 0 이 됨을 확인했다. 설계한 구조의 입·출력 에 대한 지연시간은 16 클록 (또는 4 사이클)이 소요되 고, 최초의 상태 값이 출력 된 후 지속적으로 다음 상태의 값이 출력되기 때문에 낭비되는 결과 값이 없 다.

$<$ Table $1>$ The result of efficiency evaluations of two designed QPCA structures

\begin{tabular}{|c|c|c|}
\hline & $\begin{array}{c}\text { 기존의 } \\
\mathrm{D} \text { 플립플롭을 } \\
\text { 사용한 } \mathrm{QPCA} \\
\text { 구조 }\end{array}$ & $\begin{array}{c}\text { 제안한 } \\
\mathrm{D} \text { 플립플롭을 } \\
\text { 사용한 } \mathrm{QPCA} \\
\text { 구조 }\end{array}$ \\
\hline $\begin{array}{l}\text { 총 셀의 수 } \\
\text { (단위: 개) }\end{array}$ & 395 & 289 \\
\hline $\begin{array}{c}\text { 전체 크기에 } \\
\text { 대한 셀의 수 } \\
\text { (단위: 개) }\end{array}$ & $\begin{array}{c}1,710 \\
(0.77 \mathrm{~m})\end{array}$ & $\begin{array}{c}1,056 \\
\left(0.43 \mu m^{2}\right)\end{array}$ \\
\hline 집적도 & $23.0 \%$ & $27.4 \%$ \\
\hline $\begin{array}{l}\text { 소요된 클록 } \\
\text { (단위: 클록) }\end{array}$ & 24 & 16 \\
\hline $\begin{array}{c}\mathrm{D} \text { 플립플롭의 } \\
\text { 특성 }\end{array}$ & $\begin{array}{c}\mathrm{CLK} \text { 신호를 } \\
\text { 이용 }\end{array}$ & $\begin{array}{c}\mathrm{QCA} \text { 클록킹을 } \\
\text { 이용 }\end{array}$ \\
\hline $\begin{array}{c}\mathrm{D} \text { 플립플롭의 } \\
\text { 확장성과 } \\
\text { 유연성 }\end{array}$ & 제한적 사용 & 가변적 사용 \\
\hline $\begin{array}{c}\text { 낭비되는 값의 } \\
\text { 유무 }\end{array}$ & $\begin{array}{c}\text { 회로의 } \\
\text { 지연시간에 따라 } \\
\text { 항상 존재함 }\end{array}$ & 없음 \\
\hline
\end{tabular}

설계한 두 $\mathrm{QPCA}$ 구조의 성능평가를 위해 소요된 회로의 크기와 입·출력 간의 지연시간 및 집적도를 기 준으로 비교 및 분석을 수행했다. 또한, 평가를 수행 하기 위해 총 셀의 수와 전체 회로 크기에 대응하는 셀의 수, 소요 클록을 각각 측정했고, 그 결과는 Table 1과 같으며, 이는 QCADesigner의 시뮬레이션 결과를 통해 확인 가능한 것이다. 두 $\mathrm{QPCA}$ 구조들을 설계하기 위해 사용된 총 셀의 수는 각각 395개와 289 개가 소요되었고, 기존의 $\mathrm{D}$ 플립플롭을 이용한 설계 구조가 106 개의 셀을 더 사용하였음을 확인했다. 또한 설계한 구조의 전체 크기는 각각 $0.77 \mu \mathrm{m}^{2}$ 와 $0.43 \mu \mathrm{m}^{2}$ 이고, 셀이 차지하는 면적으로 계산한 경우 각각 1,710 
개와 1,056 개가 소요되었다. 이를 통해 기존의 D 플립 플롭을 사용하는 것보다 본 논문에서 새롭게 제안한 $\mathrm{D}$ 플립플롭을 이용하는 것이 회로의 공간 측면에서 약 $55.84 \%$ 더 효율적임을 확인했다.

설계한 두 구조에 대한 집적도는 모두 낮은 편이다. 이것은 향후 연구를 통해 집적도를 높일 수 있도록 할 것이고, 소요된 지연시간은 각각 24 클록과 16 클 록이며, 이것은 서로 다른 D 플립플롭을 사용했기 때 문에 차이가 발생했다. 이를 통해 제안한 $\mathrm{D}$ 플립플롭 을 이용하는 것이 $\mathrm{QPCA}$ 의 시/공간 효율성 측면에서 우수함을 알 수 있었고, QCADesigner를 통해 설계한 $\mathrm{QPCA}$ 구조가 올바른 결과 값을 도출하는 것을 확인하 였다.

\section{5. 결 론}

본 논문에서는 $\mathrm{QCA}$ 클록킹 기법에 기반을 둔 새로 운 $\mathrm{D}$ 플립플롭을 제안하였고, 이를 이용해 $\mathrm{QPCA}$ 구 조를 설계하였다. 기존의 $\mathrm{QCA}$ 상에서 제안된 $\mathrm{D}$ 플립 플롭은 $\mathrm{CLK}$ 신호에 의해 동작이 제어되기 때문에 $\mathrm{QCA}$ 클록킹과 중복되어 사용되는 단점과 낭비되는 출력 상태 값이 존재했다. 제안한 $\mathrm{D}$ 플립플롭은 $\mathrm{QCA}$ 클록킹 기법과 이진배선의 구조를 이용해 단순한 형 태로 설계했다. 제안한 $\mathrm{D}$ 플립플롭을 이용해 설계한 $\mathrm{QPCA}$ 는 기존의 $\mathrm{D}$ 플립플롭을 이용한 $\mathrm{QPCA}$ 설계 구조와 비교해 회로의 지연시간은 8 클록을 줄였고. 공 간은 $55.84 \%$ 를 축소시켰다. 제안한 D 플립플롭과 이 를 이용해 설계한 $\mathrm{QPCA}$ 구조의 출력된 값의 정확성 을 평가하기 위해 QCADesigner를 이용하여 시뮬레이 션을 수행했고, 그 결과 입력에 대응되는 올바른 결과 가 출력됨을 확인했다.

\section{References}

[1] K. Pagiamtzis and A. Sheikholeslami, "ContentAddressable Memory (CAM) Circuits and Architectures: A Tutorial and Survey", IEEE Journal of Solid-State Circuits, Vol. 41, No. 3, pp. 712-727, 2006.

[2] B. E. Akgul, L. N. Chakrapani, P. Korkmaz, and
K. V. Palem, "Probabilistic CMOS Technology: A Survey and Future directions", Proceedings of 2006 IFIP International Conference on IEEE, pp. $1-6,2006$.

[3] G. Y. Cho, "Newton-Raphson's Double Precision Reciprocal Using 32-bit Multiplier", Journal of the Korea Industrial Information System Society, Vol. 18, No. 6, pp. 31-37, 2013.

[4] E. H. Ahn and J. R. Choi, "High Speed TCAM Design Using SRAM Cell Stability", Journal of the Korea Industrial Information System Society, Vol. 18, No. 5, pp. 19-23, 2013.

[5] P. P. Chaudhuri, Additive Cellular Automata: Theory and Applications, vol. 1, John Wiley \& Sons, pp. 52-55, 1997.

[6] A. Khurasia, and P. Gambhir, Quantum Cellular Automata, Final Project Report, 2006.

[7] A. S. Shamsabadi, B. S. Ghahfarokhi, K. Zamanifar, and N. Movahedinia, "Applying Inherent Capabilities of Quantum-dot Cellular Automata to Design: D Flip-flop Case Study", Journal of Systems Architecture, Vol. 55, No. 3, pp. 180-187, 2009.

[8] C. S. Lent, P. D. Tougaw, W. Porod, and G. H. Bernstein, "Quantum Cellular Automata", Nanotechnology, Vol. 4, No. 1, pp. 49-57, 1993.

[9] M. R. Beigh, M. Mustafa, and F. Ahmad, "Performance Evaluation of Efficient XOR Structures in Quantum-Dot Cellular Automata (QCA)", Circuits and Systems, Vol. 4, No. 2, pp. 147-156, 2013.

[10] Microsystems and the University of British Columbia Nanotechnology Group. QCADesigner, 2007, [Internet]. Available: http://www.mina.ubc.ca/ qcadesigner/.

[11] K. Walus, T. J. Dysart, G. A. Jullien, and R. A. Budiman, "QCADesigner: A Rapid Design and Simulation Tool for Quantum-dot Cellular Automata”, IEEE Trans. Nanotechnology, Vol. 3, No. 1, pp. 26-31, 2004.

[12] J. R. Janulis, P. D. Tougaw, S. C. Henderson, and E. W. Johnson, "Serial Bit-Stream Analysis 
Using Quantum-dot Cellular Automata", IEEE

Trans. Nanotechnology, Vol. 3, No. 1, pp. 158-164, 2004.

[13] H. Cho, and E. E. Swartzlander, "Adder Designs and Analyses for Quantum-dot Cellular Automata, IEEE Trans. Nanotechnology, Vol. 6, No. 3, pp. 374-383, 2007.

[14] V. Vankamamidi, M. Ottavi, and F. Lombardi, "A Serial Memory by Quantum-dot Cellular Automata (QCA)", IEEE Trans., Computers, Vol. 57, No. 5, pp. 606-618, 2008.

[15] P. D. Tougaw, and M. Khatun, "A Scalable Signal Distribution Network for Quantum-dot Cellular Automata", IEEE Trans. Nanotechnology, Vol. 12, No. 2, pp. 215-224, 2013.

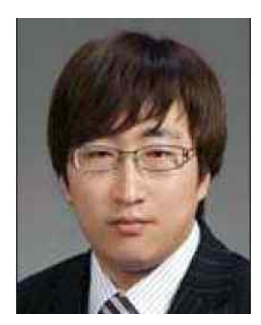

신 상 호 (Sang-Ho Shin)

- 정회원

- 금오공과대학교 응용수학과/컴퓨 터공학과 이/공학사

- 경북대학교 전자전기컴퓨터학부 공학석사

- 경북대학교 컴퓨터학부 박사수료

- 관심분야: 양자점 셀룰라 오토마타, 양자암호, 고속 암호 알고리듬 등

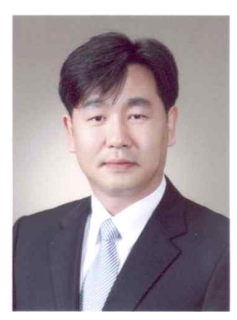

전 준 철 (Jun-Cheol Jeon)

- 정회원

- 금오공과대학교 컴퓨터공학과 공학사

- 경북대학교 컴퓨터공학과 공학석사

- 경북대학교 컴퓨터공학과 공학박사

- 금오공과대학교 컴퓨터공학과 교수

- 관심분야: 암호학, 암호회로설계, 양자암호, 양자 프 로토콜 설계 등

논 문 접 수 일 : 2014년 04월 25일

1차수정완료일 : 2014년 06월 30일

게 재 확 정 일 : 2014년 11월 10일 